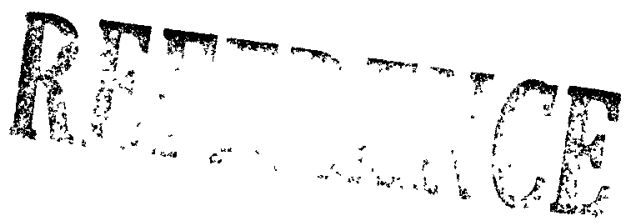

TITLE:

DATE :

AUTHOR:

APPROVED:

\section{APPLICATIONS OF STATIC CONVERTERS IN POWER CONDITIONING}

April 28, 1967

$<\sum /$ tarche

C. E. Hardies

Control Equipment

Electronics and Instrumentation

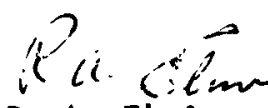

R. A. Elmiger, Supervisor

Equipment Design \& Fabrication

Control Equipment

Electronics and Instrumentation

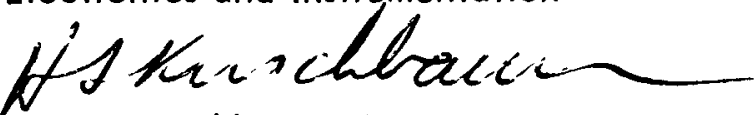

H. S. Kirschbaum, Manager

Electronics and Instrumentation

INFORMATION CATEGORY

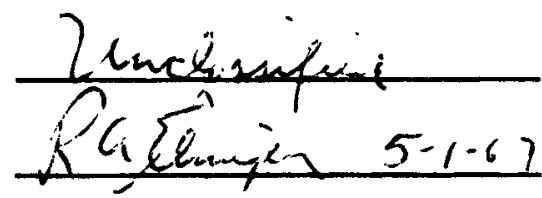

Authorized Classifier Date

NOTICE

This report was prepared as an account of work This report was Unted States Governmest. Nethe ponsored by the Unicd Sthe United States I nergy the United Stes nor any of Research and Devclopment Alling their contractors, their employees, nor any of their contrestor subcontractors, or their employees, mikes warnty, express or implied, or assumes any legal warranter the accuracy, completenes liability or responsility apparatus, product or

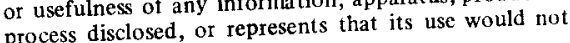
infringe privately owned rights. 


\section{DISCLAIMER}

This report was prepared as an account of work sponsored by an agency of the United States Government. Neither the United States Government nor any agency Thereof, nor any of their employees, makes any warranty, express or implied, or assumes any legal liability or responsibility for the accuracy, completeness, or usefulness of any information, apparatus, product, or process disclosed, or represents that its use would not infringe privately owned rights. Reference herein to any specific commercial product, process, or service by trade name, trademark, manufacturer, or otherwise does not necessarily constitute or imply its endorsement, recommendation, or favoring by the United States Government or any agency thereof. The views and opinions of authors expressed herein do not necessarily state or reflect those of the United States Government or any agency thereof. 


\section{DISCLAIMER}

Portions of this document may be illegible in electronic image products. Images are produced from the best available original document. 
(W) Astronuclear

\section{APPLICATIONS OF STATIC CONVERTERS IN POWER CONDITIONING}

\section{Table of Contents}

Section

$\underline{\text { Page }}$

Introduction ..................... 1

General Operational Description of Static Converters .... 2

Specific DC to DC Converter Circuits .......... 3

Evaluation of Weight, Size, and Power Losses Associated ... 8 with Power Conditioning by Means of Static Converters

Power Conditioning Considerations . . . . . . . 8

AC to DC Conversion Considerations . . . . . . . . 11

DC to AC Conversion Considerations .......... 13

Transformer Considerations. . . . . . . . . . . . 15

Efficiency Considerations ............... 16

System Considerations . . . . . . . . . . . 17

Design Factors and Considerations of DC to DC Static Converter 20

Semiconductor Switch Selection . . . . . . . . . 22

Magnetic Core Selections . . . . . . . . . . . . 23 


\section{APPLICATIONS OF STATIC CONVERTERS IN \\ POWER CONDITIONING}

\section{List of Figures}

Figure

Title

$\underline{\text { Page }}$

Functional Block Diagram DC to DC Converter ...... 3A

Basic Transistorized DC to DC Converter Circuit ..... 3B

Typical Square Hysteresis Loop B vs H Curve ....... 3C

Ideal Waveshapes DC to DC Converter of Figure 2 ... 3D

Tunnel Diode DC to DC Converter (Parallel) ...... 4A

Silicon Controlled Rectifier Static Converter Circuit ... 5A

Two Diode Weight vs Rectified Output Power at ..... 8A

Several Input Voltages

Two Diode Volume vs Rectified Output Power at .... 9A

Several Input Voltages

Transformer Specific Weight vs Frequency ...... 10A

Transformer Specific Volume vs Frequency ....... 10B

Silicon Device Power Conversion Percentage Efficiency . . IIA vs Input Voltage

Germanium Device Power Conversion Percentage Efficiency 11B vs Input Voltage 
Q Astronuclear

\section{APPLICATIONS OF STATIC CONVERTERS IN POWER CONDITIONING}

Introduction

The purpose of this report is to acquaint the thermoelectric generator design groups with some of the types of static converters and how they work. In addition, information is presented showing how to figure out the approximate efficiency, weight, and volume of a unit required for a given input voltage and power handling capability. Examples are included to show how one figures the approximate efficiency, weight, and volume of a unit for specified input voltage and power handling capability using the curves of Figures 7 through 12.

Particularly pertinent are the curves on Figures 11 and 12 which show the predicted efficiency of units at various input voltages. Significantly, the curves indicate that above approximately 10 volts input voltage the efficiency of the static converters is almost constant. Below 10 volts the curves indicate the penalty in efficiency one must pay to use this type device. The curves are shown down to one volt; however, the germanium curve, Figure 12, can be extended down to approximately $50 \%$ efficiency at 0.5 volts, if particular care is taken in the converter design.

The descriptions and data presented are for conventional D.C. to A.C. converters with square wave outputs. Specific output characteristic requirements such as sinusoidal output waveshapes, restrictions on rise and fall times on the square wave outputs, synchronizing circuitry, and the like, will affect all of the approximations.

Where special characteristics are encountered the methods described should not be used. The Electronics and Instrumentation Department should be consulted to provide the 
detailed circuitry design requirement and size, weight, and efficiency penal ties involved due to these special requirements.

One major area of interest not treated in the report is reliability. Historically the reliability of this type unit has been good, however, how good is not accurately known. A reliability study evaluating the reliability of these devices versus the reliability of thermoelectric generators at various voltages would permit a better evaluation of the area where the use of static converters penalize the overall system reliability and the area where the system reliability is increased by their use.

The characteristics of the various circuits discussed are determined by the particular static switching elements, the transformer, and the rectifiers if used. The selections of which combination of components should be used is determined by the input voltage and power levels and the output requirements.

\section{General Operational Description of Static Converters}

Static converters are devices which change or transform a D.C. voltage level to a different A.C. or D.C. level just as transformers change one A.C. voltage level to a different one. In fact, the static converter accomplishes the voltage transformation by first converting the input D.C. to an A.C. voltage, transforming the A.C. to the new level in a transformer, and if desired, rectifying the A.C. back to D.C. at the desired level. Figure $I(a)$ is a block diagram showing the three essential operational blocks: the D.C. to A.C. converter, the transformer, and the rectifiers. Figure I(b) shows a practical implementation of these three blocks. The switch is shown as a mechanical switch rather than a static switch for clarity. The switch is operated manually at a constant rate, connecting the input D.C. alternately to the two ends of the center-tapped transformer. The transformer is thus excited with an alternating voltage which in magnitude is equal to twice the input D.C. voltage. The output of the transformer is equal to the tums ratio, $\frac{N 2}{N 1}$, times the input voltage. This transformed voltage is then converted to the desired 
output D.C. voltage level in the rectifier section.

It should be noted that the inclusion of a static inverter, between the thermoelectric generator and user output, permits the generator to be designed for optimum performance, essentially independent of the user load requirements except for the magnitude of the power required by the load.

Specific D.C. to D.C. Converter Circuits

The transformation and rectification functions as shown in Figure $l(b)$ are common to all of the static converter circuits. The physical construction of the transformer can be on a laminated core or on a toroidal tape wound core, however, the differences are relatively small in terms of operation. These differences will be discussed later. The rectifiers also affect the circuit operation only to a minor degree as will be discussed. The main differences in static converter designs is in the elements which are used for chopping the input D.C.

Figure 2 shows a basic transistorized D.C. to D.C. converter circuit. The transistors $Q_{1}$ and $Q_{2}$ are utilized as switches, being either saturated or open circuited, with their state depending on the polarity of the signal to their base terminals (b). The transformer can be either laminated or toroidal, but must have essentially a square hysteresis loop as shown on Figure 3. Some materials which display this type hysteresis loop characteristic are Hy MU80, 4-79 Permalloy, Orthonol, and 48 Alloy to name just a few. Different materials which display this general loop characteristic will have greatly different magnitudes for $\mathrm{B}_{\max }$ and $\mathrm{H}_{c}$. For example:

$\begin{aligned} & \text { Orthonol } \\ & \text { Orthonik } \\ & \text { Deltamax }\end{aligned}$
$\begin{aligned} & \text { Hy MU80 } \\ & 79 \text { Square MU } \\ & \text { Square Permalloy }\end{aligned} \mid \begin{aligned} & \mathrm{B}_{\max } \approx 15 \times 10^{3} \text { Gauss } \\ & \mathrm{H}_{\mathrm{c}} \approx 0.2 \text { oersteds at } 60 \mathrm{cps}\end{aligned}$
$\mathrm{B}_{\max } \approx 7 \times 10^{3}$ Gauss
$\mathrm{H}_{\mathrm{c}} \approx 0.04$ oersteds at $60 \mathrm{cps}$



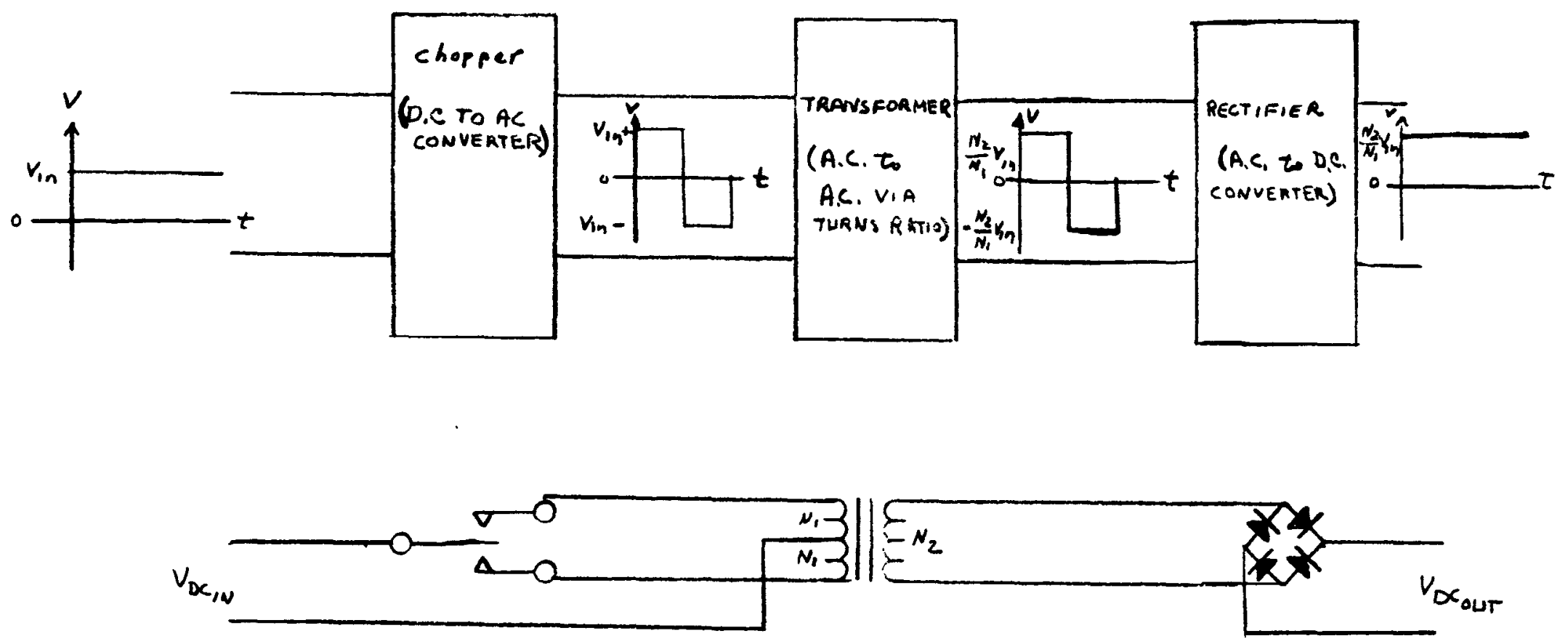

Figure 1

Functional Block Diagram

$D C$ to $D C$ Converter 


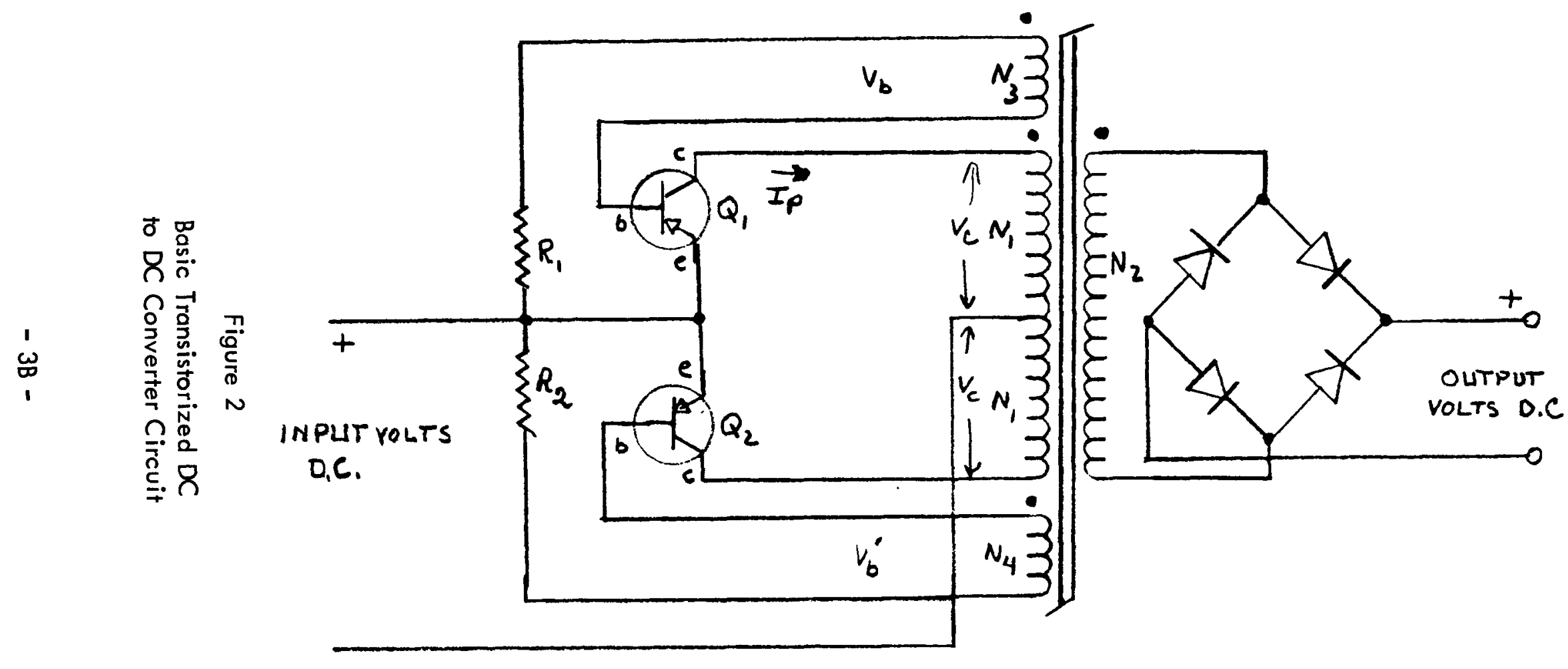

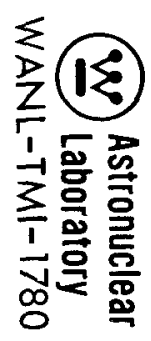




\section{(W) Astronuclear}

WANL-TMI- 1780

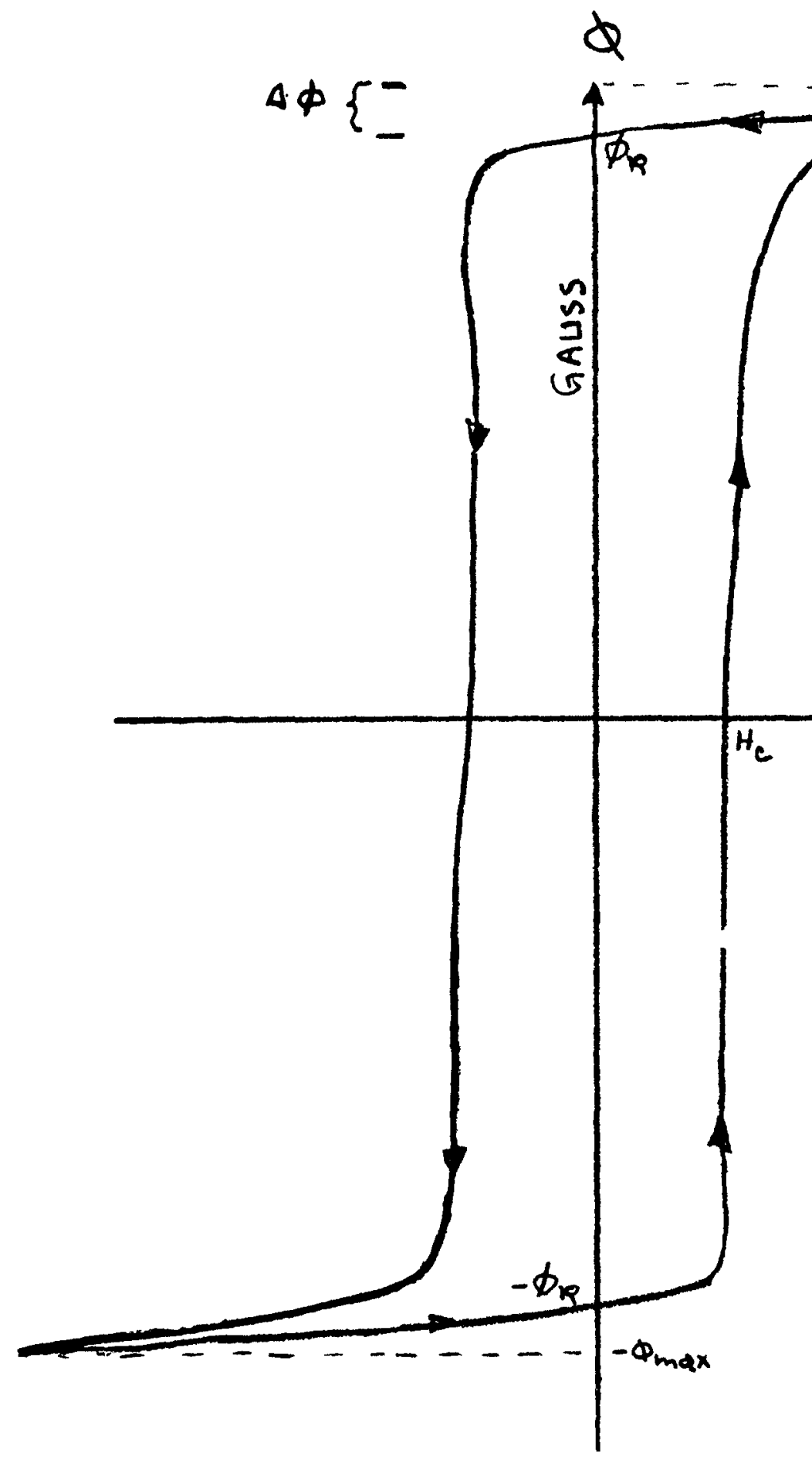

Figure 3

$$
\begin{gathered}
H_{c}=\frac{.4 \pi N I_{m}}{\text { mein Length of core }} \\
\phi=\beta \times A_{C} \\
B=\text { core FLUX DEUsm } \\
A_{c}=\text { Cross section AL } \\
\text { Ared of CORE }
\end{gathered}
$$

Typical Square Hysteresis Loop B vs H Curve 


\section{Astronuclear

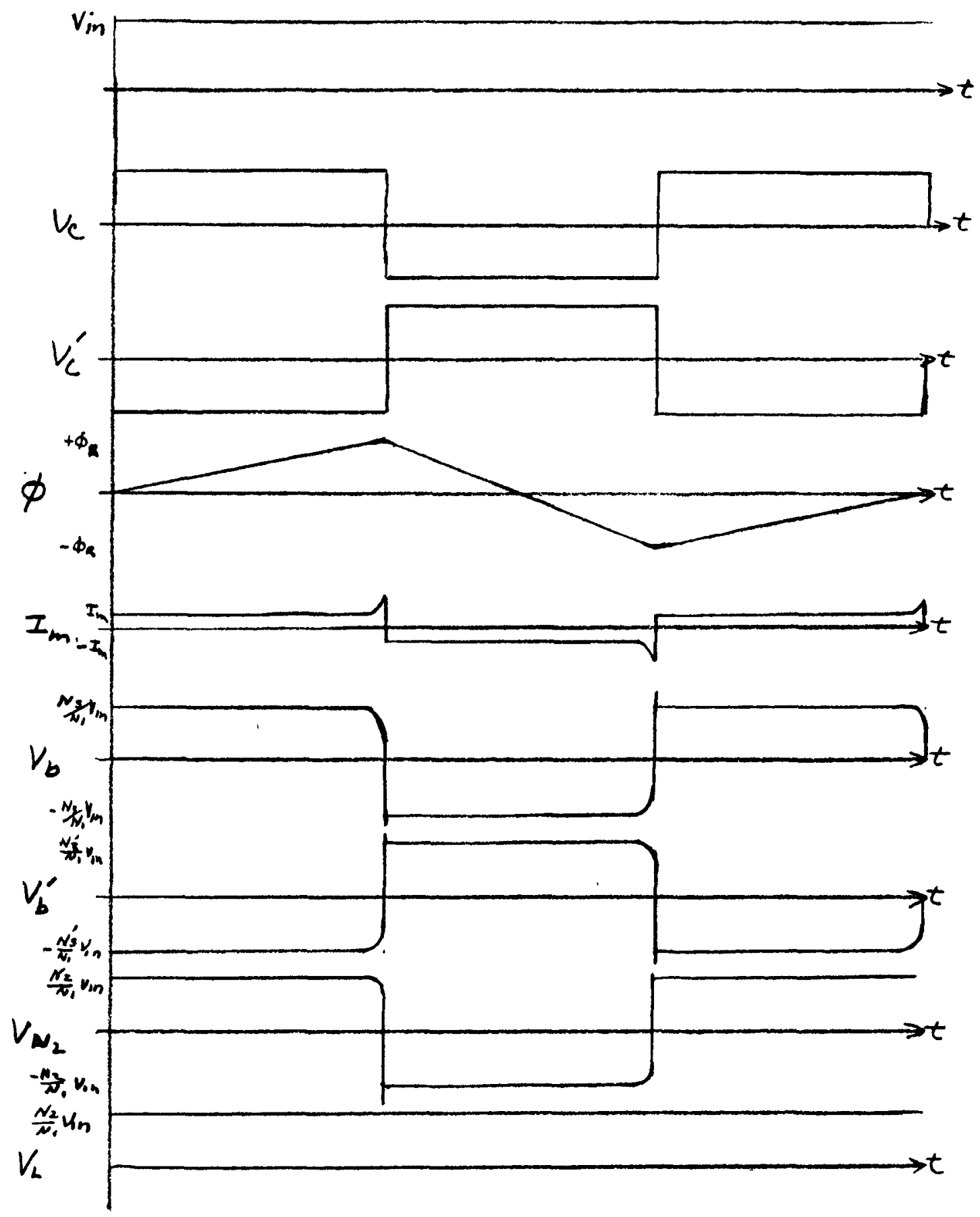

Figure 4

Ideal Waveshapes

$D C$ to $D C$ Converter of Figure 2 
The choice of the core material and construction depends upon the detailed circuit performance requirements. The effects of transformer materials and construction will be discussed further in the section on converter detailed design procedures.

The operation of the circuit of Figure 2 is as follows. Assume transistor $Q_{1}$ is "on", or short circuit, and the core flux starts at $-\phi_{\max }$ (see Figure 3). Winding $N_{1}$ is connected across the power supply due to the assumed short circuit condition of Transistor $Q_{1}$. The polarization of the transformer is such that the induced voltages are instantaneously the same at all the dots. The core flux changes in the positive direction until it reaches approximately $\varnothing_{R}$ (see Figure 3). During this time a voltage is induced in winding $N_{3}$ which is equal to the furns ratio $\left(\frac{N 3}{N 1}\right)$ times the applied voltage to the primary winding $V_{c}$. This voltage through resistor $R_{1}$ provides the base currrent to maintain transistor $Q_{1}$ in its saturated condition. In like manner the voltage induced in winding $\mathrm{N}_{4}$ which is equal to $\frac{N 4}{N 1}$ is applied to Transistor $Q_{2}$ through Resistor $R_{2}$. In this case, however, the polarity is such that the transistor is held "off" or open circuited. During this interval the voltage induced in the load windings $N 2$ is equal to $\frac{N 2}{N 1} V_{c}$. Once the core flux reaches $\varnothing_{R}$, an increase in core flux is accompanied by an increase in coercive current (the current required to drive the core material). This decreases the rate of change of flux and therefore, the induced voltages. As a result, Transistor $Q_{1}$ comes out of saturation, removing the applied voltage from winding $N_{1}$. When this occurs the core flux drops to the residual level $\phi_{R}$. This flux change, $\Delta \varnothing$ on Figure 3 , is opposite in polarity to the flux change previously discussed. The induced voltage in windings $N_{3}$ and $N_{4}$ are opposite to their previous polarities. Transistor $Q_{2}$ has a forward bias and assumes its saturated mode while Transistor $Q_{1}$ is reverse biased and is "off" or open circuit. The input D.C. is now applied to winding $N_{1}$ and the core flux changes in the direction of $-\phi_{R}$. Once the flux reaches $-\phi_{R}$ the same action occurs as previously discussed when the flux approached $+\phi_{R}$. The waveshapes for the parameters discussed are shown on Figure 4. It should be pointed out that these waveforms are for idsal components (transistors, diodes, and transformer). When practical components are used the parameters depart from those of Figure 4. The amount of 


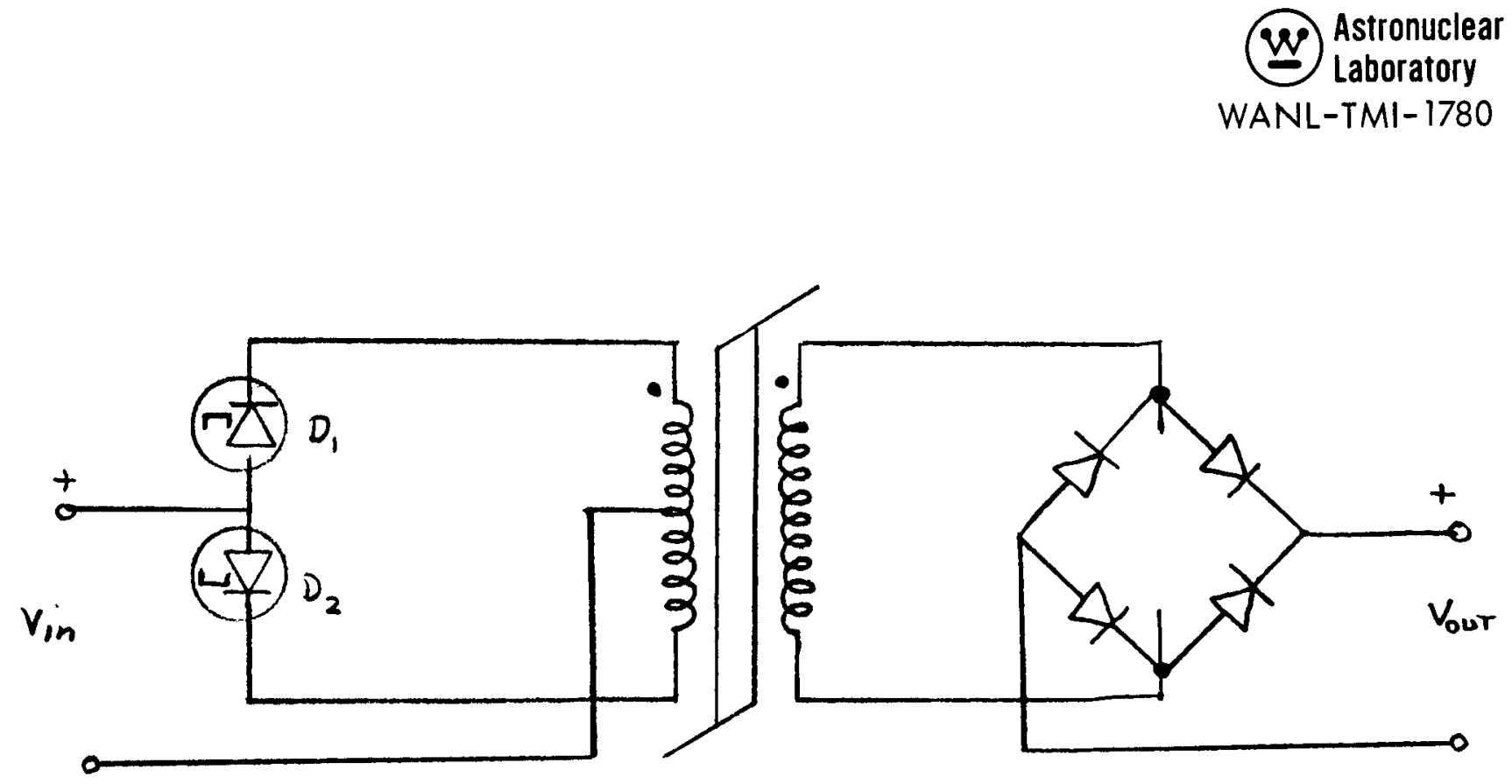

Figure 5(a)

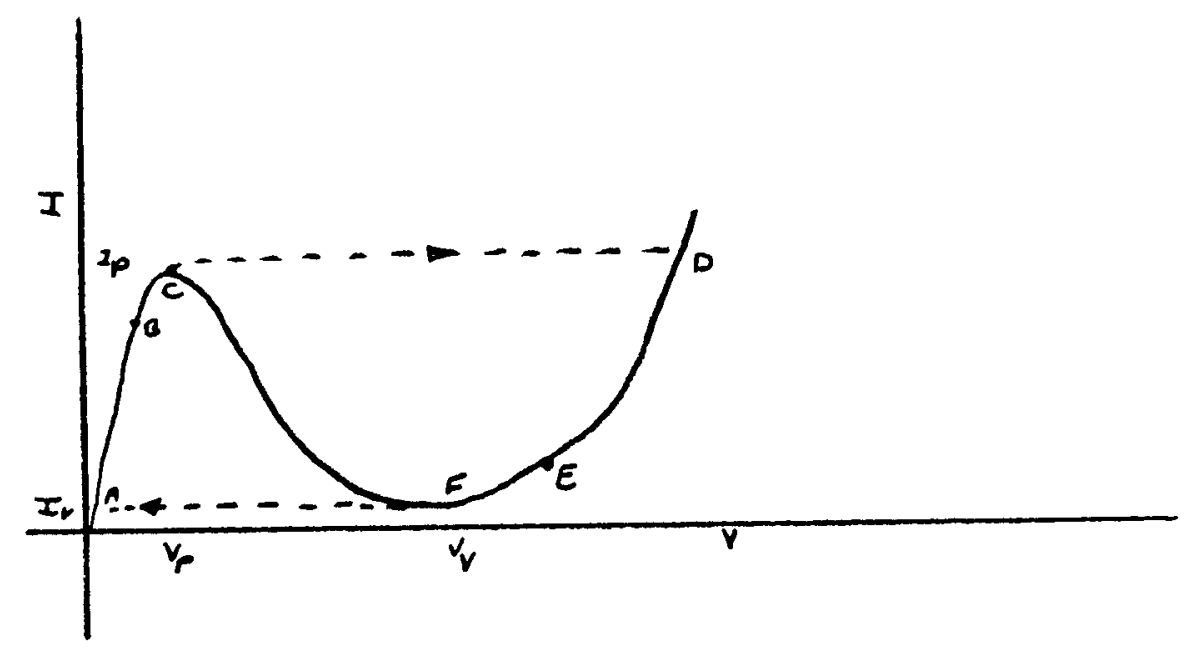

Figure 5(b)

Figure 5

Tunnel Diode DC to DC

Converter (Parallel) 


\section{(W)

departure is a measure of the losses in the system. These losses will be discussed in detail later since they determine the efficiency in the converter.

Other switching elements can be utilized as the switches in the circuit of Figure 2; specifically, Tunnel Diodes, silicon controlled switches, or as previously mentioned, mechanical vibrators or choppers.

Figure 5 is a schematic of a Tunnel Diode D.C. to D.C. converter. The circuit is simpler than the transistorized converter of Figure 2 in that no feedback from the transformer is required. The Tunnel Diodes operate as switches as in the transistor designs, however, the negative resistance inherent in the Tunnel Diode produces the two state switching function. The circuit operates as follows: The transformer in this circuit must have a hysteresis loop characteristic similar to that of Figure 4 as in the previous circuit. Assume that Diode $D_{1}$ has just switched to its high current state. This switching induces a voltage across the primary in such a direction as to force Diode $D_{2}$ to switch from its high state to its low state. The induced voltage across the primary windings then has a polarity that maintains the first Diode $D_{1}$ in its high state and the second Diode $D_{2}$ in its low state. This induced voltage remains until the flux in the core reaches $\phi_{\text {sat }}$ (the transformer saturates) where the current would increase rapidly. When the flux change stops, the induced voltages collapse, causing the diodes to switch to their opposite states. They remain in this state while the core flux drops to $-\varnothing_{\text {sat }}$ (the transformer saturates in the opposite direction). Unlike the transistorized circuit D.C. to D.C. converters there is no sudden large increase in current through the diodes when the core saturates because the decrease in flux rate of change switches the diodes. While the Tunnel Diode circuit is extremely simple, it suffers the disadvantage that its efficiency is quite low as compared to the transistorized circuit, this occurs as a result of the low operating (input) voltage required for the tunnel diodes, and further because the "on" to "off" voltage and current ratios are quite low. The operating voltage for germanium tunnel diodes is approximately $0.15 \mathrm{VDC}$ and for silicon approximately $0.4 \mathrm{~V}$. The diode efficiency, $\mathrm{N}_{0}$, can be expressed by these ratios: 


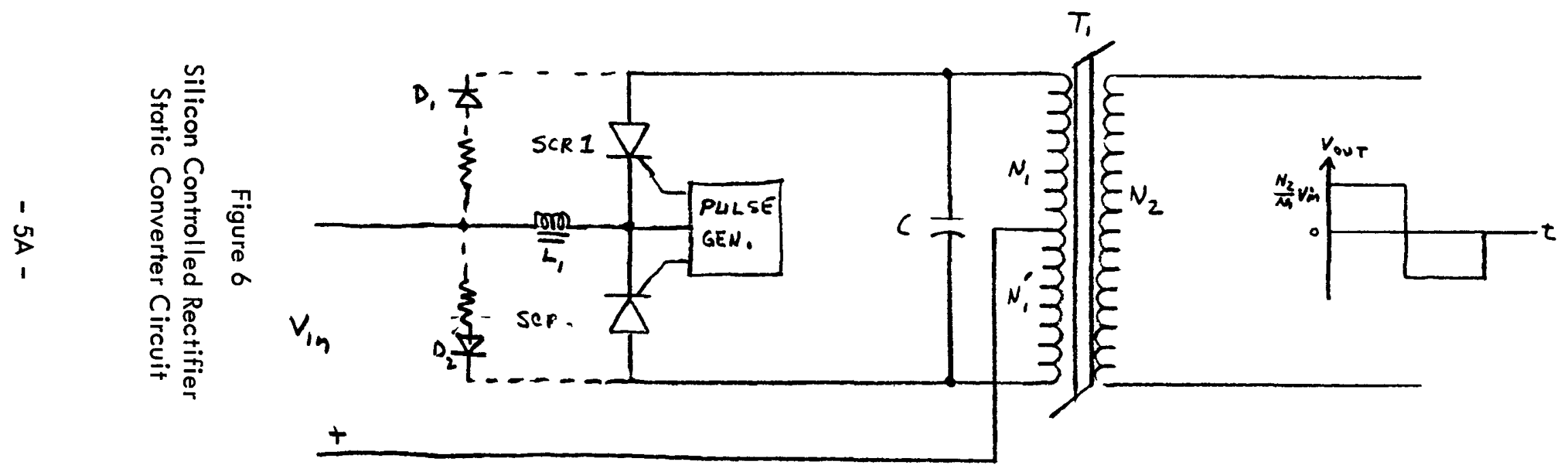

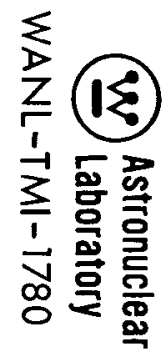




$$
N_{0}=\frac{\left(I_{p}-I_{v}\right)\left(V_{v}-v_{p}\right)}{\left(I_{p}+I_{v}\right)\left(V_{r}+V_{p}\right)} \quad 100
$$

Voltage and current ratios for presently available Tunnel Diodes run as high as $I_{p} / I_{V}=15$ and $V_{v} / V_{p}=9$.

Overall circuit efficiencies run as high as $50 \%$ presently with 60 to $70 \%$ possible by use of more advanced diodes.

Another semiconductor which is used in static converters is the silicon controlled rectifier. Figure 6 is a schematic of a typical converter circuit using these devices. The output of this circuit as in the transistor and Tunnel Diode converters discussed is essentially a square wave which is rectified to obtain an output D.C. The operation is as follows: The oscillator circuit provides positive trigger pulses al ternately to the gates of SCRI and SCR2. Assume that SCR1 is conducting and SCR2 is blocking. The current from the supply, $V_{i n}$, flows through the left hand side of the transformer $T_{1}$; namely, through winding $N_{1}$. The transformer action produces a voltage of approximately $2 V_{\text {in }}$ at the anode of SCR2 and across the capacitor $C$. When the next trigger pulse is applied to the gate of SCR2, it will furn on and the voltage at the anode of SCR2 will fall to a value equal to the forward conducting drop, 0.5 to 1.0 volt. The voltage at the anoide of SCR1 will fall to approximately $-2 \mathrm{~V}_{\text {in }}$ because of the action of the commutating capacitor $C_{1}$. This capacitor will maintain a reverse bias across SCRI long enough for SCRI to recover to its blocking state. The next trigger pulse will occur at the gate of SCRI and cause the circuit to revert to the original state. The inductor $L_{1}$ serves as a ballast to prevent excessive current flow during switching since during the switching interval current can flow in both halves of the transformer primary to the commutating capacitors and to the anode of the $S C R$ which has been turned on. If the current is not limited the charging time for the commutating capacitor will be very short and the SCR which is to be turnet off will not be reverse biased long enough for it to recover. Large values of $L_{1}$ on the other hand will 
prevent the supply from adjusting to rapid changes in the load.

The parallel SCR inverter discussed above presents a problem with varying load conditions, for the correct amount of commutating capacity can be selected for only one load value. Under light load conditions, the reduced load current makes the waveform depart considerably from a square wave and the peak $S C R$ voltage can rise to several times the supply voltage. This condition is accentuated if the load is reactive. By including commutating diodes across the SCR's (dotted circuitry of Figure 6) the problem can be minimized, in that the voltage across either half of the transformer is prohibited from exceeding the supply voltage. The diodes also compensate for leading or lagging power factor loads by feeding the reactive power back into the supply.

The pulse generator of Figure 6, which provides the pulses to turn "on" the SCR's alternately can be one of the previously discussed inverter circuits where the output power of the circuit is very low. The main advantage of the SCR inverter as discussed is in high power applications where the base drive to operate transistor s'vitches becomes high. The SCR has an internal feedback which causes it to remain in the saturated state once switched there until its anode voltage is reduced below the value which produces sufficient anode current to maintain the SCR in its conducting mode.

Other devices which can be utilized in static converters are field effect transistors and silicon controlled switches. These devices can be utilized in low power inverters directly in the configuration of Figure 2, where the FET units replace the transistors. The silicon controlled switches have the disadvantage that they must be biased "on", requiring more complexity than the basic inverter circuit of Figure 2. This offsets their advantage of requiring only turn "on" and "off" pulse power and their inherent high blocking voltage capability. 
WANL-TMI- 1780

Evaluation of Weight, Size, and Power Losses Associated with Power Conditioning By

Means of Static Converters

The information presented in this section is based on a study by the Equipment Development Section at Westinghouse Research Laboratories. This in formation permits one to estimate the size, weight, and power loss associated with integrating a static converter into an electrical power system, in this case a thermoelectric generator system, for the purpose of power conditioning the output. The information is presented in graphical or tabular form for ease of manipulation. By using the procedures described it is possible to estimate the weight, volume, and efficiency of a static converter based on the input voltage level and power transferred within the limits of the assumptions made.

Power Conditioning Considerations

In the determination of this information several assumptions were made. Comments concerning the validity of these assumptions are included below. Specific assumptions made for a particular system are listed under the individual system descriptions.

1) Assumption: For semiconductor junctions the reverse leakage current is considered to be negligible with respect to the forward current capability.

Comment: This assumption will hold for relatively low voltage systems. However, when the scheme under consideration is both high voltage and low power, the reverse leakage may be an appreciable portion of the forward current. This reservation should be considered when working with systems above 500 volts at power levels below 50 watts. It should also be noted that the leakage current roughly doubles for every $10^{\circ} \mathrm{C}$ increase in temperature. This can also make the leakage current appreciable at elevated temperatures and should not be ignored in systems required to function in high temperature environments. 


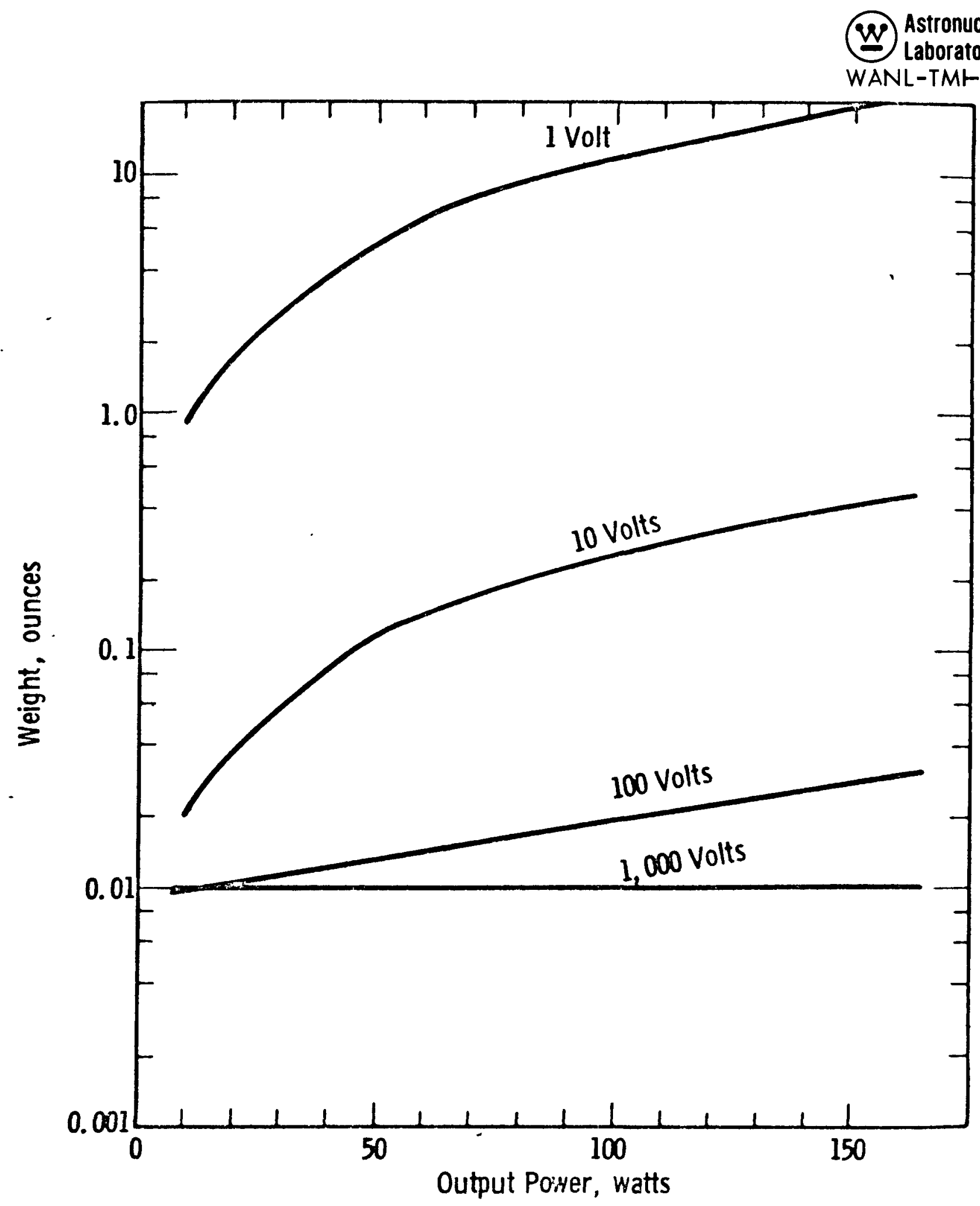

FIGURE 7 -Two dicde weight vs rectified output power at several input voltages 
2) Assumption: The semiconductor recovery time is negligible.

Comment: This assumption will hold for low and intermediate frequency systems. However, when dealing with systems above $100 \mathrm{KHZ}$ the recovery interval may become an appreciable portion of the half-cycle period. This is especially true when considering currents above 5 amperes where the increased bulk of semiconductor (required to handle the current) requires a longer period to "sweep out" the carriers from the junction and regain a blocking mode.

3) Assumption: The forward voltage drop of a silicon junction is 0.7 volts while that of a germanium junction is 0.3 volts.

Comment: This assumption is reasonable under most conditions. However, both these figures are somewhat temperature dependent. This could lead to appreciable changes with low voltage systems at extreme temperature. A commonly accepted value for this temperature coefficient is $-2.5 \mathrm{mv} /{ }^{\circ} \mathrm{C}$.

4) Assumption: The power rating of a system is the power delivered to the load. Comment: This standard assumption is made simply to clearly define the method of determining the power capability of a particular system.

5) Assumption: A semiconductor device can be constructed in any desired rating within the range of this analysis.

Comment: This assumption has been made to permit a smooth information transition from one device current and vol tage level to another. The information, therefore, represents the parameters of devices that would be utilized if they were made exactly at the desired rating. A particular device availability at either extreme of voltage and current is unlikely. For instance, silicon transistor ratings seldom exceed 200 volts and 100 amperes. Any further increase in demands made on the device would have to be met by penalties or a change in the type of device utilized. Hence, a high voltage or high 


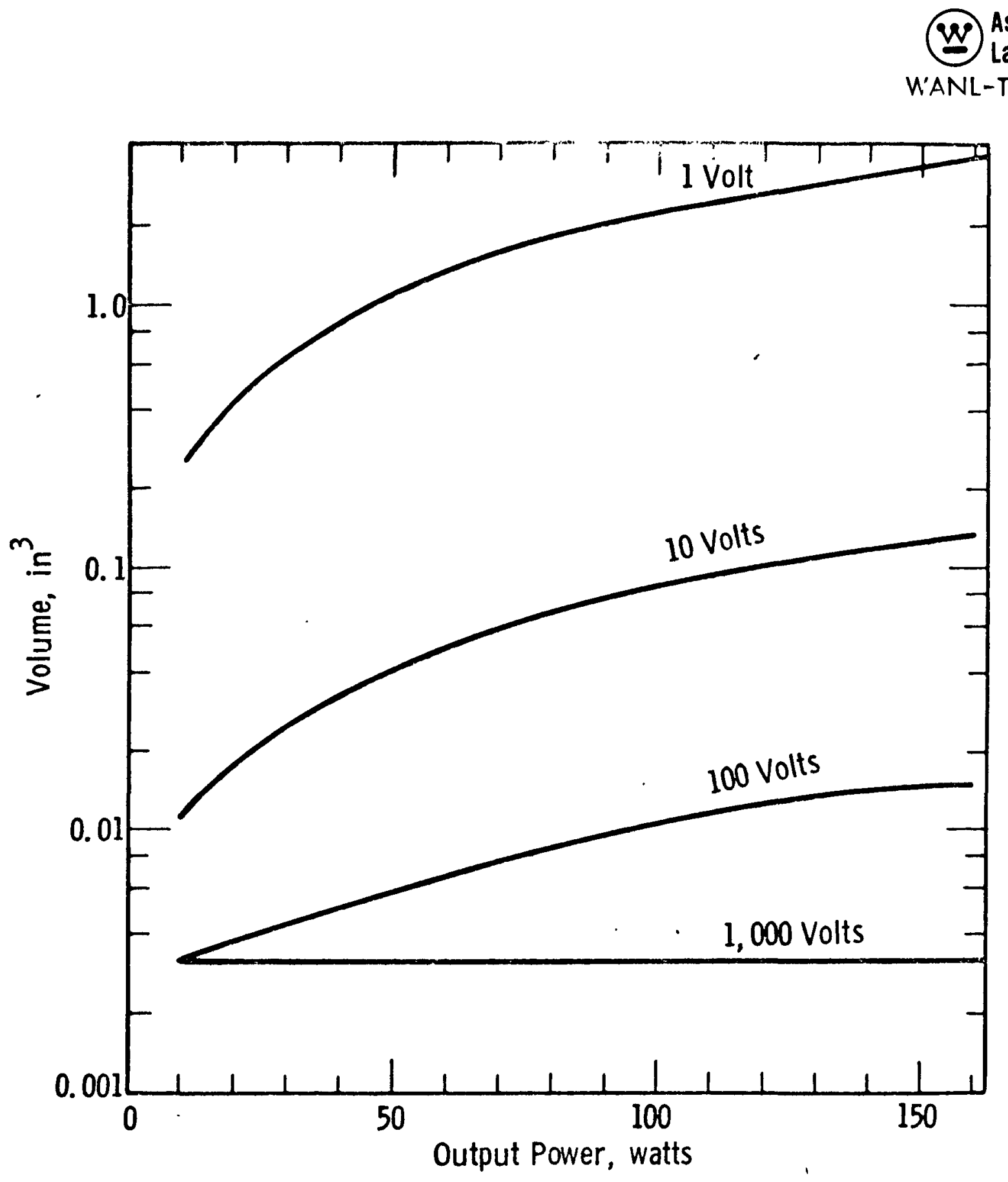

FIGURE 8 -Two diode volume vs rectified output power at several input voltages 


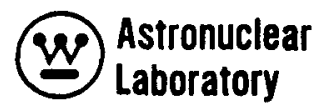

WANL-TMI- 1780

current transistor system might be made more attractive if the transistors are functionally replaced with thyristors. This type of substitution is generally dependent upon the specific application and design goals. Reservations which should be observed as a result of this assumption are listed below.

a) Germanium devices are seldom rated above the following limits:

Diodes - 500 volts; 100 amps

Transistors - 100 volts; 70 amps

b) Silicon devices are seldom rated above the following limits:

Diodes - 1200 volts; 400 amps

Transistors - 200 volts; 100 amps

Thyristors - 1200 volts; 400 amps

As a result of these limitations, it is reasonable to expect that the high voltage and/or high current areas which require an active device would be dominated by thyristors circuitry.

6) Assumption: The efficiency of all transformers is $94 \%$.

Comment: This assumption is valid for most cases and is based on previous standard information and designs.

7) Assumption: Each semiconductor is provided with a heat sink held at constant temperature of $100^{\circ} \mathrm{F}$ (about $40^{\circ} \mathrm{C}$ ).

Comment: This is a basic assumption agreed upon as one of the ground rules of the analysis. It eliminates the need for calculating the necessary heat sink. If, for a particular application, the assumption were not true, separate investigations should be conducted concerning the required cooling process.

When considering the necessary heat sink, it would be reasonable to first determine the system losses, then choose a method of cooling (forced or natural convection) 


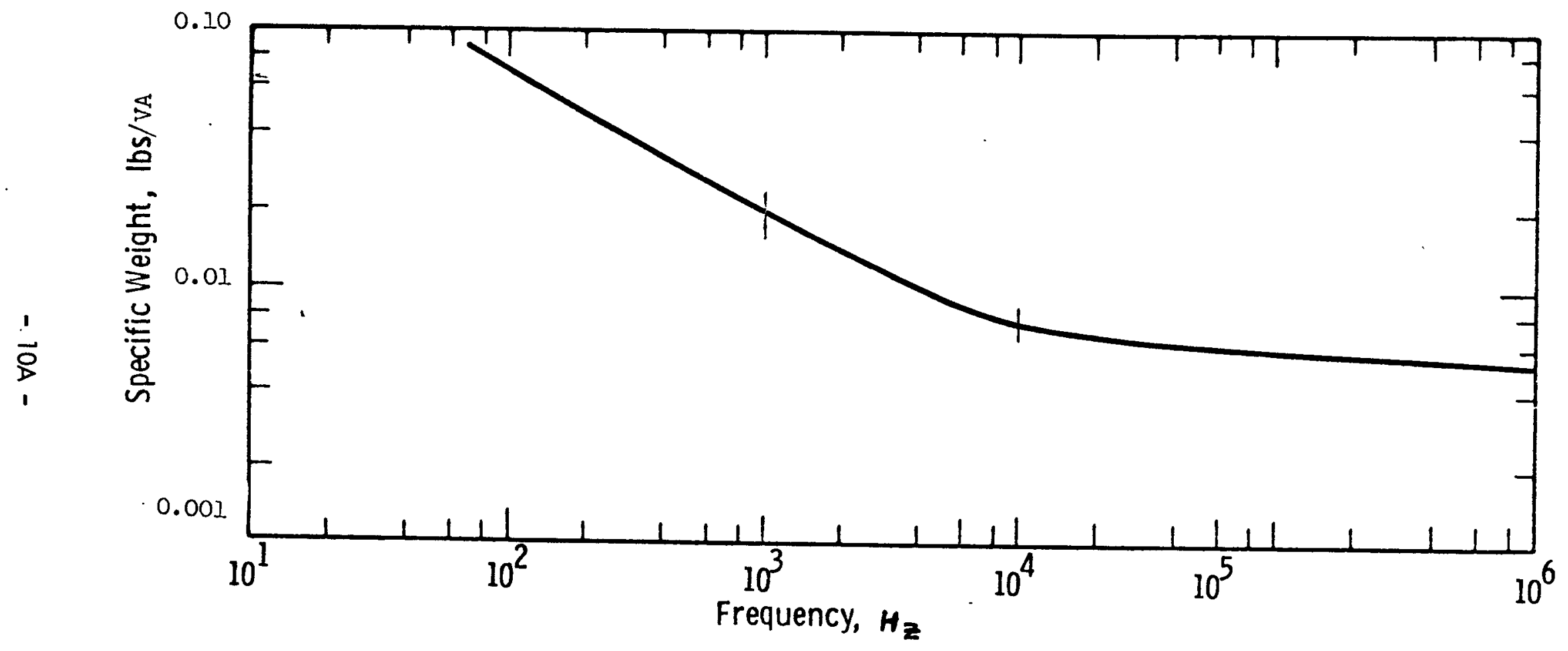

FISURE 9 -Transformer specific weight vs frequency 
1
0
0
1

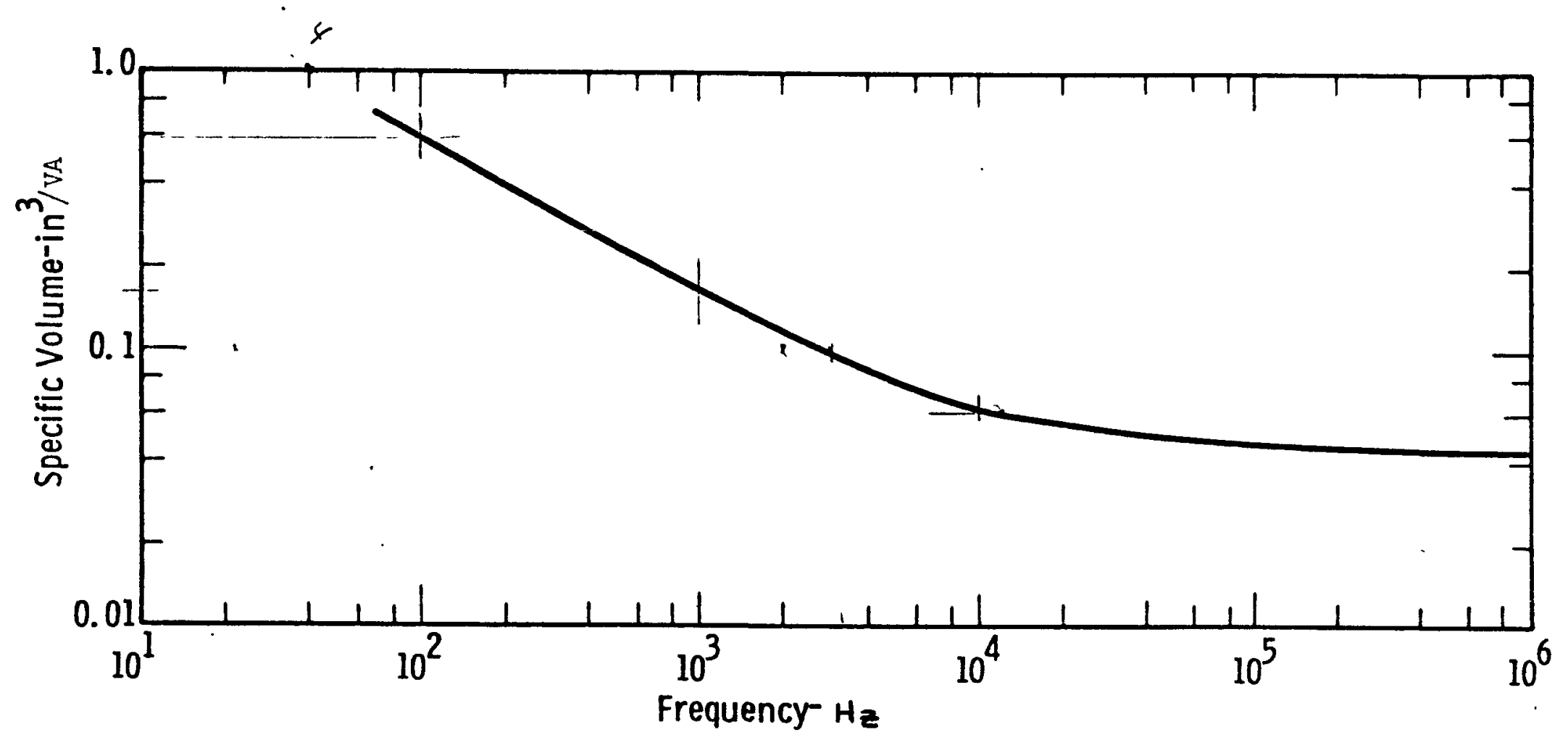

FIGURE 10 -Transformer specific volume vs frequency 
(2.) Astronuclear

and add to the calculated system size and weight the following quantities:

Forced Convection Cooling

$$
\begin{aligned}
& \text { Weight }=\text { (Losses) }(0.5 \mathrm{oz} / \text { watt }) \\
& \text { Volume }=(\text { Losses })(0.1 \mathrm{in} / \text { watt }) \\
& \text { Natural Convection Cooling } \\
& \text { Weight }=\text { (Losses) }(0.5 \mathrm{oz} / \text { watt }) \\
& \text { Volume }=\text { (Losses) }(2 \mathrm{in} / \text { watt })
\end{aligned}
$$

If forced convection cooling is used on higher power systems, it might be possible to direct the coolants through existing spaces in the system. In this case, the additional weight and volume would be negligible.

\section{AC to DC Conversion Considerations}

Several specific assumptions were made in the analysis of $A C$ to $D C$ power conversion (rectification). These assumptions, with appropriate comments, are listed below.

1) Assumption: The output current is carried through one of the devices at all times.

Comment: This assumption is valid for a basic rectifying scheme using a centertapped $A C$ source and two rectifiers. If, for a particular application, the full wave, four rectifier approach is more attractive, thenany numbers derived from the graphs depicting losses, weight, and volume of $A C$ to $D C$ rectification should be modified.

The choice of a two device or a four device system depends mainly upon the system configuration. In $A C / D C$ application, if a center tapped source is available, a two device rectifier scheme would offer the most advantage. In a DC/AC application the optimum system would be where a center tapped load would permit the use of a two device inverter. In either case, if the tap is not available, a four device scheme would have to be used to perform the function. The two device or four device choice also depends, to a lesser degree, upon the voltage of the system. With a two device scheme each device must 


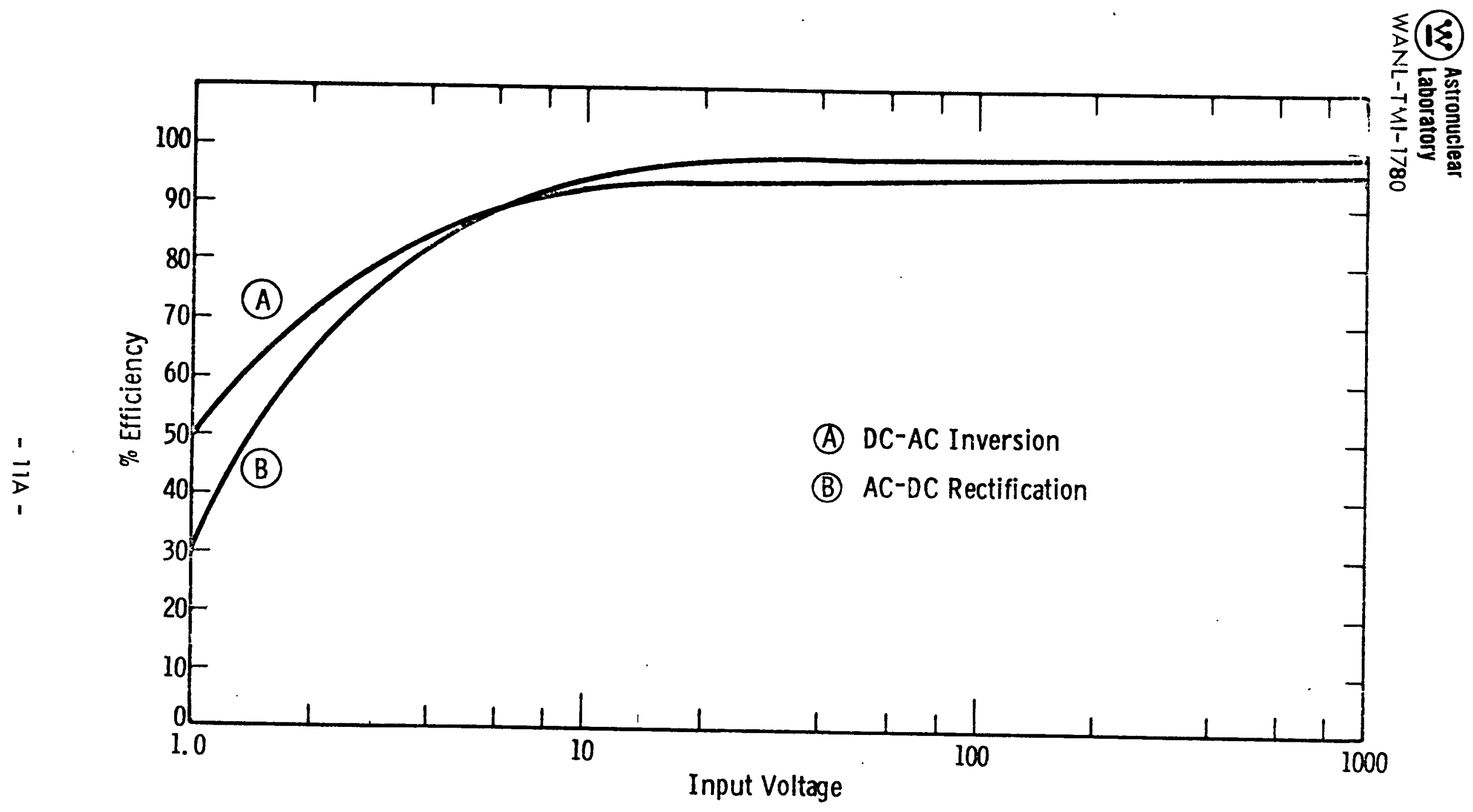

FI SURE 11 -Silicon device power conversion percentage efficiency vs input voltage 


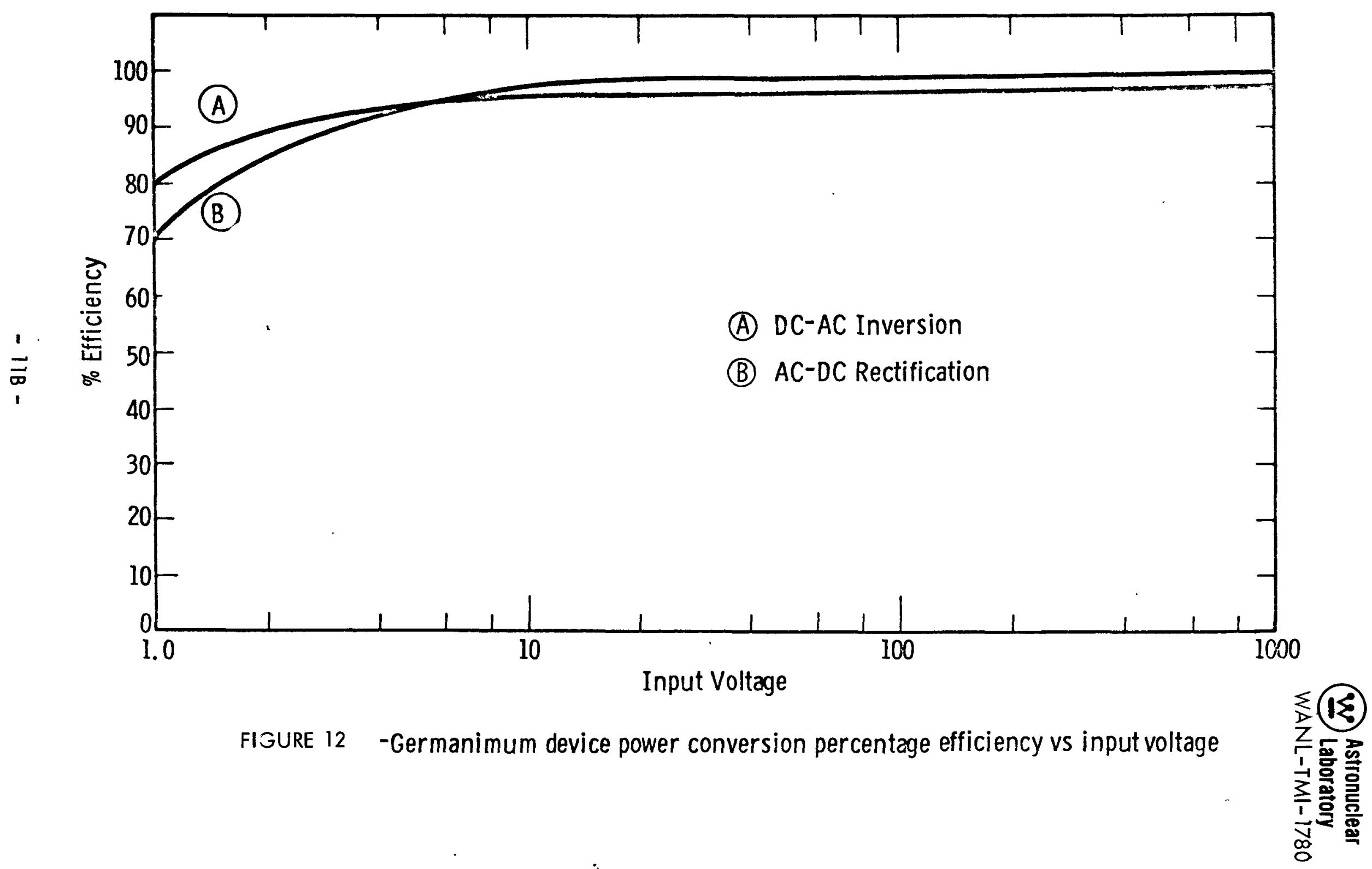


have a rating at least twice the input voltage (from one side to center tap). Using the four device configuration, each device can be rated at the input voltage. Hence, at high voltage applications, it is sometimes advantageous to use the four device scheme because of the ratings of available components.

2) Assumption: The rectification occurs from a square wave source.

Comment: This assumption was made to permit rapid and accurate calculation of the device parameters. If sine wave inputs are assumed, the device ratings depend, to a great extent, on the type of filter used to smooth the $D C$ voltage and/or current. The resulting device current is difficult to analyze in a direct manner without a specific circuit as a design goal. The assumption will lead to a slight deviation from the theroretical data in the information, but this deviation will remain insignificant for the majority of systems that would normally be considered.

3) Assumption: The smallest available two diode package weighs no less than $10^{-2}$ ounces or has a volume no less than $3.1 \times 10^{-3}$ cubic inches.

Comment: This assumption is reasonable because, even if the actual semiconductor material becomes smaller than the assumed values, the fabrication and mounting procedures would probably increase the total weight and volume of the final package to these figures. In most cases, these numbers would represent such a minor fraction of the weight and volume in a complete system that further reductions would be difficult to justify. Indeed, penalties in quality, assembly, and cost might be the result of attempts to reach lower values than assumed as minimum weights.

The results of investigations concerning the weight and volume of $A C$ to $D C$ power conditioning apparatus are graphically displayed in Figures 7 and 8, respectively. In both cases the results are plotted as a function of system input voltage and output power. 
Hence, to arrive at the weight or volume of a particular rectifier scheme

a) Determine the required power rating.

b) Determine the system working voltage.

c) Use a) and b) to determine the system weight or volume from Figure 7 or 8 .

d) Multiply by any factor associated with the number of devices.

$$
\begin{aligned}
& \text { factor }=2 \text { for } 4 \text { device single phase. } \\
& \text { factor }=3 \text { for } 6 \text { device three phase. }
\end{aligned}
$$

Example: Determine the weight and volume of a four device $A C$ to $D C$ silicon rectifier whose power capability is 100 watts and whose input voltage is 10 volts.

a) Power $=100$ watts

b) Voltage $=10$ volts

c) Two device weight $=0.25$ ounces (Figure 7)

Two device volume $=0.084$ in. ${ }^{3}$ (Figure 8$)$

d) Devices $=4$ hence, multiply both weight and volume by 2

System Weight $=(0.25)(2)=0.5$ ounces

System Volume $=(0.084)(2)=0.168$ cubic inches

$D C$ to $A C$ Conversion Considerations

Several specific assumptions were made in the analysis of $D C$ to $A C$ power conversion (inversion). These assumptions with appropriate comments are listed below.

1) Assumption: The output current is carried through one of the devices at all times.

Comment: This assumption is valid for a basic inversion scheme using a centertapped load and two devices. If, for a particular application, a single phase bridge (4 devices) or a three phase bridge ( 6 devices) is used, any numbers derived from the graphs depicting losses, weight, and volume of $D C$ to $A C$ inversion should be modified. 
2) Assumption: The inversion results in a square wave output.

Comment: Since efficiency is one of the major goals of the investigations, and device switching is the most efficient process of power control, square wave outputs will result from the most efficient $D C$ to $A C$ conversion process.

3) Assumption: The switching device weight and volume is approximately one and one-half times the weight and volume of a diode of comparable rating.

Comment: This assumption is valid for the majority of controlled semiconductors used in power conversion apparatus. This would include transistors, thyristors, unijunction transistors, field effect transistors, etc. The assumption is based on comparison of existing devices and on the practical considerations that a switching device generally has half again as much semiconductor bulk, and at least one more junction, than a diode.

Hence, to arrive at the weight or volume of a particular inversion scheme

a) Determine the required power rating.

b) Determine the system working voltage.

c) Use a) and b) to determine the two diode weight and volume from Figures 7 and 8.

d) Multiply the result of 3 by 1.5 to get the weight and volume of a two device inversion scheme.

e) Multiply by the factor associated with the number of devices.

$$
\begin{aligned}
& \text { factor }=2 \text { for } 4 \text { device single phase bridge. } \\
& \text { factor }=3 \text { for } 6 \text { device three phase bridge. }
\end{aligned}
$$

Example: Determine the weight and volume of a four device $D C$ to $A C$ silicon inverter whose power capability is 100 watts and whose input voltage is 10 volts.

a) Power $=100$ watts

b) Voltage $=10$ volts

c) Two Diode Weight $=0.25$ ounces

Two Diode Volume $=0.084$ cubic inches

d) Two Device Weight $=(0.25)(1.5)=0.375$ ounces

Two Device Volume $=(0.084)(1.5)=0.126$ cubic inches 
e) Devices $=4$ hence multiply both weight and cubic volume by 2

System Weight $=(0.375)(2)=0.75$ ounces

System Volume $=(0.126)(2)=0.252$ cubic inches

\section{Transformer Considerations}

Two major assumptions were made in the analysis of transformer parameters. These assumptions, with appropriate comments, are listed below.

1) Assumption: All transformers under consideration have ferro-magnetic cores.

Comment: In the transformer considerations, air core unit parameters were calculated. Since the information indicated that the air core transformers offered no advantage at frequencies below a megahertz (especially in the volume considerations), their use as a circuit component was not further considered.

2) Assumption: At a given frequency there is a specific relationship between the power rating of the transformer and its weight and size.

Comment: This assumption is valid over a small range of power levels. Since the investigations were performed from 5 va to 150 va the assumption will produce very little error.

No assumptions were made concerning the use of transformers; as a consequence, the information may be regarded as having very few additional reservations if the transformers are used in a conventional manner.

The information resulting from the transformer investigation is shown graphically in Figures 9 and 10. These figures represent the per unit weight and volume of a transformer at various frequencies.

Hence, to determine the weight or volume of a transformer

a) Determine the working frequency.

b) Determine the desired power level.

c) Use a) to determine the per unit parameters for the transformer from Figures 9 or 10 . 
d) Use b) and c) to determine the parameter of the desired transformer by multiplying the desired power level times the appropriate per unit value.

Example: Determine the weight and volume of a 50 va transformer at a working frequency of $10 \mathrm{KHZ}$.

a) Frequency $=10 \mathrm{KHZ}$

b) Power $=50 \mathrm{va}$

c) Weight $/ \mathrm{va}=0.0075 \mathrm{lbs} / \mathrm{va}$ Volume/va $=0.062 \mathrm{in} 3 / \mathrm{va}$

d) $x$ fmr weight $=(50)(0.0075)=0.375 \mathrm{lb}$ $x \mathrm{fmr}$ volume $=(50)(0.062)=3.1$ cubic inches

\section{Efficiency Considerations}

The results of the investigations concerning the efficiency of various power conditioning schemes are graphically displayed in Figures 11 and 12.

Figure 11 indicates first, the conversion efficiency of silicon devices in $D C$ to $A C$ configurations; and, second, the conversion efficiency of silicon devices in $A C$ to $D C$ configurations.

Figure 12 is similar to Figure 11 except the semiconductor material used for the device construction is germanium instead of silicon. It should be noted that above approximately 10 volts the efficiencies of silicon and germanium are very nearly the same. It is for this reason that the weight and volume are based on the use of silicon devices since they are more prominent in the semiconductor field (generally because of their increased temperature and voltage capability). This change does not represent any significant error since the weight and volume of a germanium device would be very nearly the same as a silicon device of the same rating. 
Hence, to arrive at the efficiency of a particular system

a) Determine the system working voltage.

b) Determine the system working mode ( $\mathrm{dc} / \mathrm{dc}$ or $\mathrm{dc} / \mathrm{ac}$ ).

c) Use a) and b) to determine the system efficiency from Figures 11 and 12 .

d) Multiply by any factor associated with the number of devices.

e) Multiply by 0.94 if a transformer is to be included in the system.

\section{System Considerations}

\section{Dual Conversion}

For $D C$ to $A C$ or $D C$ to $D C$ conversion both the rectifying and inversion processes are generally used. In the case of $D C$ to $A C$ conversion the power must only be inverted to $A C$ at the desired frequency and voltage level. In the case of $D C$ to $D C$ conversion the power must first be inverted to an intermediate frequency and voltage level then, rectified to produce the desired output level. Since the power, in either of the dual conversion processes, is handled by two of the methods previously described, the determination of the size and weight will be a combination of all the previous information.

Of major importance in the dual conversion scheme is the operating frequencies of the transformer.

The optimum frequency will be determined by the individual system and can be chosen to minimize the size and weight of the transformer. Semiconductor size and weight can generally be minimized by higher voltages and lower currents while the transformer weight and volume will be reduced (at a given power level) where the working frequency is highest.

Hence, to determine the parameters of a dual conversion scheme

a) Determine the power level.

b) Determine the input and output voltage and frequency requirements. 
(W) Astronuclear

WANL-TMI-1780

c) Determine the optimum frequency for the transformer.

d) Separate and calculate the parameters of the DC to $A C$ operation.

e) Separate and calculate the parameters of the $A C$ to $D C$ operation.

f) Determine the parameters of the transformer involved.

g) Combine the results (by addition) of d), e), and f) to arrive at the parameters of the dual conversion system.

h) Determine the efficiency of the overall scheme by using the dual conversion curve of Figure 11 or the separate values if the voltages are different. Include $94 \%$ efficiency of the transformer.

Example: Determine the weight, volume and efficiency of a DC to DC power conditioning scheme with 50 watt capability. The input voltage will be 10 volts and the output should be 24 volts DC.

a) Power $=50$ watts

b) Input $=10$ volts $D C$

Output $=24$ volts $D C$

c) Transformer frequency should be as high as possible to minimize weight and size, consistent with switching speed of the transistor switches. Use $10 \mathrm{KHZ}$ as operating frequency.

d) $D C$ to $A C$ operation

Input power $=$ output req/overall efficiency

$=50 / 84.25=59.5$

since $D C$ to $A C$ eff. at $10 \mathrm{~V}=92, A C$ to $D C$ at 24 volts eff. $=97 \%$, and transformer eff. $=94 \%$

$$
92.5 \times 97 \times 94=84.25 \%
$$

voltage $=10$ volts

weight $=0.065$ ounces (from Figure 7 ) $\times 1.5=0.0975$ ounces

volume $=0.0235$ cubic inches (from Figure 8 ) $\times 1.5=0.3525$ cubic inches 
e) Transformer

frequency $=10 \mathrm{KHZ}$

power $=52 \times 0.94=49.0$ watts

since $A C$ to $D C$ rectifier $98 \%$ efficient at 20 volts

weight $=(49.0)(0.0075)=0.368$ pounds

volume $=(49.0)(0.062)=3.04$ cubic inches

f) $A C$ to $D C$ operation

power $=50$ watts

voltage $=24$ volts

weight $=0.06$ ounces

volume $=0.022$ cubic inches

g) System Volume

System Weight

$x f m r=3.04$ in $^{3}$

$x \mathrm{fmr}=5.89$ ounces

$A C / D C=0.022$

$A C / D C=0.06$

$D C / A C=0.03525$

$D C / A C=0.0975$

Total

$$
3.09 \text { in }^{3}
$$

Total

6.05 ounces

h) $D C$ to $A C$ efficiency $=92 \%$

transformer efficiency $=94 \%$

$A C$ to $D C$ efficiency $=97 \%$

system efficiency $=92 \times 94 \times 97=84.25 \%$

\section{Control Functions}

In most of the power conversion circuitry where active devices are a functional necessity a certain amount of control circuitry is mandatory. This is especially true if a particular power circuit is to be controlled over a range of voltage, current or frequency. Although the amount of control circuitry depends upon the complexity of control desired, 
the size and weight should be approximately an order of magnitude below that of the power circuit. Hence, if a proposed circuit is to contain a reasonable amount of control, it would be acceptable to increase the size and weight of the basic power circuit by 10 to $15 \%$ to include this auxiliary control.

\section{Waveshaping}

In instances where a square wave output is obtained from an inverter, it is sometimes desirable to alter the waveshape such that the result is more representative of a sine wave. The waveshaping components genrally are in the form of a reactive element so that a reasonable system efficiency is maintained. In the most commonly used circuit the waveshaping is in the form of a series L-C circuit resonant at the fundamental frequency. The weight and volume of a filter to reduce a square wave to a $5 \%$ distortion sine wave would be approximately 2.5 times the size of a transformer that handles an equivalent amount of output power.

\section{Reactive Loading}

In systems, especially $D C / A C$ systems, where the load can be reactive, it is necessary to construct circuitry that permits reverse current flow through the apparatus. Most commonly this capability takes the form of reverse current diodes. Each power switching device is shunted, in the reverse direction, by one of these diodes. The volt-amp capability of the system remains unchanged but the power rating of the DC/AC circuit is reduced due to this reactive loading.

\section{Design Factors and Considerations of DC to DC Static Converter}

In designing a solid state $D C$ to $D C$ or $D C$ to $A C$ converter there are a number of factors to be considered, and depending on the design criteria, the importance of certain factors may influence the design. All static inverters can be resolved into the simple 
circuit of Figure 2 where the semiconductor switches may be any of the devices previously discussed. The energy required to operate the semiconductors as switches is supplied by the feedback from the windings $\mathrm{N}_{3}$ and $\mathrm{N}_{4}$ to the bases of the transistors (Figure 2) or by the inherent bistable characteristic of the tunnel diodes (Figure 5) or by an external pulse generator with SCR's (Figure 6). Other semiconductors which could be utilized as the switches would use one of these three methods of powering the devices. The iron core of the transformer is utilized fully in that the flux is driven to positive and negative saturation on alternate half cycles and induces in all windings an alternating square wave voltage. This square wave may be delivered directly to the load or rectified to $D C$ at a voltage higher or lower than the source voltage depending on the turns ratio and circuit losses according to the following equation:

$$
V_{\text {sec }}=\frac{N_{1}}{N_{2}} \quad N_{\text {in }}-\text { Requiv. I }{ }_{p}
$$

where Requiv. is the sum of the primary resistance (transformer wire resistance and transistor saturated impedance), and the resistance in each of the secondary windings reflected to the primary through the turns ratio squared. The voltage spike on the leading edge of each half cycle (see Figure 4) is produced by the inductive kickback of a switch opening an inductive circuit, in this case the transistor tuming off. This voltage pulse generated by one switch opening is the means by which the other switch is turned on, hence serves a useful purpose. If the pulse is too high, however, there is danger of damage to the switches. For this reason it is desirable to use magnetic materials in the transformer which have a rectangular hysteresis loop such that at saturation the windings exhibit low inductance and little induced kickback. Studies on semiconductors failures found in DC to $D C$ converters indicate that most, if not all, failures are not attributed to "wear out." Rather, it appears that failures can occur due to design problems in the circuit. Specifically two types of secondary breakdown failures have been found. One is a result of high 


\section{(2.) Astronuclear}

WANL-TMI- 1780

collector currents, and the other due to high voltage in the collector base junction.

\section{Semiconductor Switch Selection}

The semiconductor switches, when employed in circuits similar to that of Figure 2, must be selected to withstand at least twice the maximum input voltage. When one transistor is on, the transistor which is off must block the input voltage, plus the induced input voltage in the primary winding, plus transient spikes (which can be as high or higher than source vol tage). Transient voltage suppression circuits may be employed across the transistors to eliminate excessive voltage transients, but in any event the maximum voltage ratings for the switches must be selected to be higher than twice the maximum input voltage.

The exact limits of safe operation of semiconductor switches are sometimes not too easily determined, particulary when the transistor is operated outside its class A power rating (Extending Power Transistor Safe Areas for Fast Switching Pulses, R. Greenburg, Motorola Applications Engineering Report No. 87, December, 1962). The appropriateness of the design should be checked once the unit has been constructed by making a $V$ vs. I plot on the switch. This can easily be done by displaying collector emitter voltage vs. collector current on an oscilliscope and observing the transient characteristics.

The transistor switch frequency cut-off characteristic must be selected to be high as compared to the actual switching frequency. If the transistor cannot switch rapidly between the states of saturation and cut-off, excessive junction heating will occur and, as a result, conversion efficiency will be low. A general rule of thumb which is sometimes applied is to use a transistor whose frequency cut-off is ten times the operating frequency. Actual rise time requirements of the output may modify the selection of the transistor in this respect.

The transistor used should have as high gain as possible particularly if the converter efficiency is to be maximized. The power consumed in operating the switches must be 
obtained from the source through the transformer. It is necessary to provide current limiting resistors in the base circuits, but the $12 R$ losses in this resistance should be small to achieve high efficiencies. Hence, the $\mathrm{N}_{1} / \mathrm{N}_{3}$ and $\mathrm{N}_{1} / \mathrm{N}_{4}$ ratios should be as high as possible, yet $\mathrm{N}_{3}$ and $\mathrm{N}_{4}$ adequate to provide sufficient voltage and current to saturate the transistors at high collector currents.

The basic materials used in the manufacture of transistors are the semiconductor materials which lie between the metals and insulators in their ability to conduct electricity. The two semiconductors now being used are germanium and silicon. The maximum operating junction temperature on germanium is $85^{\circ} \mathrm{C}$ to $100^{\circ} \mathrm{C}$ whereas the maximum operating junction temperature on silicon is $175^{\circ} \mathrm{C}$ to $200^{\circ} \mathrm{C}$ depending on the type units. In any application it is vital to consider the temperature which the unit will operate in. While static converters utilize the transistors as switches and, therefore, avoid the problem of changes in operating point as a result of temperature variations, still the maximum operating junction temperature must be observed. Forced or natural convection cooling may be utilized by putting the transistors on properly designed heat sinks and the like. The majority of static converter designs will utilize silicon devices as a result of the above-mentioned higher temperature characteristics and in addition the inherent advantage of higher blocking voltage capabilities inherent in silicon. On the other hand at very low voltages the low forward voltage drop of germanium makes them attractive in this class of applications.

Magnetic Core Selections

The choice of core material for a given converter design can be simplified by considering only two different kinds of material. These two materials are:

a) $50 \% \mathrm{~N}_{i}-\mathrm{Fe}$, grain oriented such as orthonol

b) $79 \% \mathrm{~N}_{\mathrm{i}}-\mathrm{Fe}$, such as Permalloy 80 


\section{(20) Astronuclear}

WANL-TMI-1780

Orthonol has a high maximum flux density with low losses, whereas Permalloy 80 has about 0.5 the maximum flux density of Orthonol, but has much lower losses, in fact, only onetenth the losses of Orthonol. This means that in most power applications where a given voltage and frequency are required, the best choice is Orthonol. By choosing the higher flux density material, less iron and copper are required, hence maximum miniaturization and high efficiency are obtained. The efficiency is high because the core losses are small compared to the output power which may be many watts. It is interesting to note that high efficiencies can be attained at high audio frequencies because as the frequency is increased, the core size is decreased, hence the increased core loss density is offset by the reduction in core volume as the frequency goes up.

On the other hand, when the converter design calls for a voltage at low power levels such as DC supply for photo tubes and Gieger tubes where high efficiencies are desired under light load conditions, Permalloy 80 should be selected.

Usually such equipment is designed for portable use where it is desired to have high efficiencies at light loads to conserve battery power. For this type of application, core losses may be greater than the power delivered to the load unless cores having extremely low losses are used, hence the choice of a core material should be that material which has the lowest losses.

The effects of windings on circuit characteristics should be appreciated by the converter designer both for the case of too few windings and excessive windings. An appreciation of this can direct the designer to the selection of an appropriate core size for a particular application.

Switching is initiated by core saturation. The change in impedance of the core from the unsaturated state to its saturated state produces a rapid tum off of the transistor. Thus, for proper operation there must be a significant change in the core impedance as it proceeds into saturation. For this reason, there must be sufficient number of turns on the core to produce this change in impedance. The primary windings $N_{1}$ should be ten turns or 
greater and $\mathrm{N}_{2}$ should be five turns or greater to insure proper operation of the circuit. An excessive number of turns on the core can result in an apparent increase in magnetizing current due to interwinding capacitance. Winding capacitance is further evidenced by ringing or spurious oscillations produced when the core is excited with a square wave input. Some of this effect can be reduced by progressive sector winding, but it is best to limit windings to a maximum of about 2,500 tums. An optimum design, to give a minimum cost of core and winding, based on keeping output turns below 2, 500 can result in an economical and efficient unit.

When a simple $D C$ to $D C$ conversion is the object of the converter designer and there are no specifications for the operating frequency, the designer has a choice as to which size core to choose. Where power conversion is to be made, the load current dictates the size of the wire in the output windings. The supply voltage is usually a fixed value so the turns ratio may be established between primary and secondary.

Thus, $N_{S} / N_{P}=V_{\text {out }} / N_{\text {supply }}$

The size of the primary windings may then be found by determining the primary current. Thus, I primary $=N_{S} / N_{P} I_{\text {load }}$ If either $N_{P}$ or $N_{S}$ can be established, then the total cross section of all windings can be found, thus establishing the window area (the required hole size in the toroid) of the cores. The total flux capacity $\left(\phi_{t}\right)$ of the core may be determined as follows:

Using $1 / 10$ the frequency rating of the transistor as the operating frequency, and knowing the supply voltage, the core flux $\phi_{t}$ may be determined from $V=2 \phi_{t} N_{1} f \times 10^{-8}$ Thus, $\phi_{t}=\frac{V}{2 N_{1} \times f \times 10^{-8}}$ 
where: $\quad V=$ supply voltage in volts

$f=$ frequency in $\mathrm{HZ}$

$\mathrm{Bm}=$ flux density of core in Gauss

$A_{c}=$ effective core cross sectional area in $\mathrm{cm}^{2}$

For first approximation, use 10 turns for $N_{j}$. If upon calculating $\varnothing_{t}$, a core is not available which has the required flux capacity a new calculation should be made using a lower frequency or a smaller cross section core. Notice that the core flux will vary inversely with frequency and turns.

Usually in power converter design, the frequency of the transistor will distate the maximum frequency of oscillation since the operating frequency of the converter should be $1 / 10$ the frequency rating of the transistor, as mentioned previously in the section on transistor selection.

Steps used to select core size, turns, and wire size for converter, inverter design:

1) The input voltage, the output power and voltage must be known. The switching frequency or the output frequency of the inverter must also be known or determined from the transistor ratings.

2) Assume a minimum efficiency of $80 \%$ and calculate the input power and the input or primary current.

3) Select the wire size for the secondary $\left(N_{S}\right)$ using a $100 \%$ duty factor and the wire size for the primary $\left(N_{p}\right)$ using a $50 \%$ duty factor.

4) Determine the $W_{a} \varnothing_{t}$ product required from the formula:

$$
W_{a} \varnothing_{t}=\frac{V A_{w}}{2 K f \times 10^{-8}}
$$


where: $W_{a}=$ Case window area in circular mils

$\phi_{+}=$Total core flux in maxwells

$V=$ Applied voltage in volts

$A_{w}=$ Wire area in circular mils

$f=$ Switching frequency

$K=$ Winding factor (In power converters assume $1 / 2$ of the available winding area is used for both primary windings. Since the primary turns $\left(N_{p}\right)$ are the turns on one side of a center-tapped winding, then $K$ equals $1 / 4$ of the nominal winding factor of 0.4. Therefore, $K=0.1$ )

5) Select a core from the Core Data Section with a $W_{a} \varnothing_{t}$ product closest to the value calculated in Step 4). The core $W_{a} \varnothing_{f}$ product can be determined from the formula:

$$
\begin{aligned}
W_{a} \phi_{t}=W_{a} \times 2 \times B m \times A c \\
\text { Where: } B m=\text { Flux density of core material } \\
A c=\text { Effective core cross sectional area } \\
W a=\text { Case window area }
\end{aligned}
$$

In selecting the thickness of core material use $.004 "$ or .006" thickness for designs operating below $100 \mathrm{HZ}$. Use .002" thickness below 2,000HZ, .001" thickness below $4,000 \mathrm{HZ}$. Ultra thin materials such as $.0005^{\prime \prime}$ thickness can be used up to $20 \mathrm{KHZ}$ while $.00025^{\prime \prime}$ thickness can be used to $75 \mathrm{KHZ}$. Above $75 \mathrm{KHZ}, .000125^{\prime \prime}$ thick material is suggested.

6) Solve for $N_{p}$ from the formula:

$$
N_{p}=\frac{V}{2 \phi_{f} f \times 10^{-8}}
$$

7) Determine the secondary turns:

$$
N_{S}=\frac{N_{p} V_{\text {out }}}{V_{\text {in }}}
$$


8) Feedback turns $N_{f}$ should apply at least one volt to drive the bases of the transistors.

$$
N_{f}=\frac{N_{p} \times 1}{V_{\text {in }}}
$$

If $N_{f}$ is less than five turns from above formula, use five turns for $N_{f}$.

Wire size for $\mathrm{N}_{f}$ is determined from the transistor characteristics. Current flowing in feedback winding $I_{f}=\frac{I_{c}}{P}$. Refer to wire table for wire size.

9) Check if core case will accommodate windings from formula.

$$
K=\frac{\left(2 N_{p} A_{w 1}\right)+\left(N_{s} A_{w 2}\right)+\left(N_{f} A_{w 3}\right)}{W_{a}}
$$

$K$ should be between 0.3 and 0.4 . It is the stacking or winding factor for the wire vs. window area inside of the core, based on toroidel winding machine winding.

10) If core case is too small select a size larger and repeat the calculations until the windings can be put on the core with a stacking factor of less than 0.4. 
WANL-TMI- 1780

Wire Data

Sizes, Areas, Resistance and Current Capacities for Synthetic Film Insulated Wire

Wire Area (Max.) * (Circular mils)

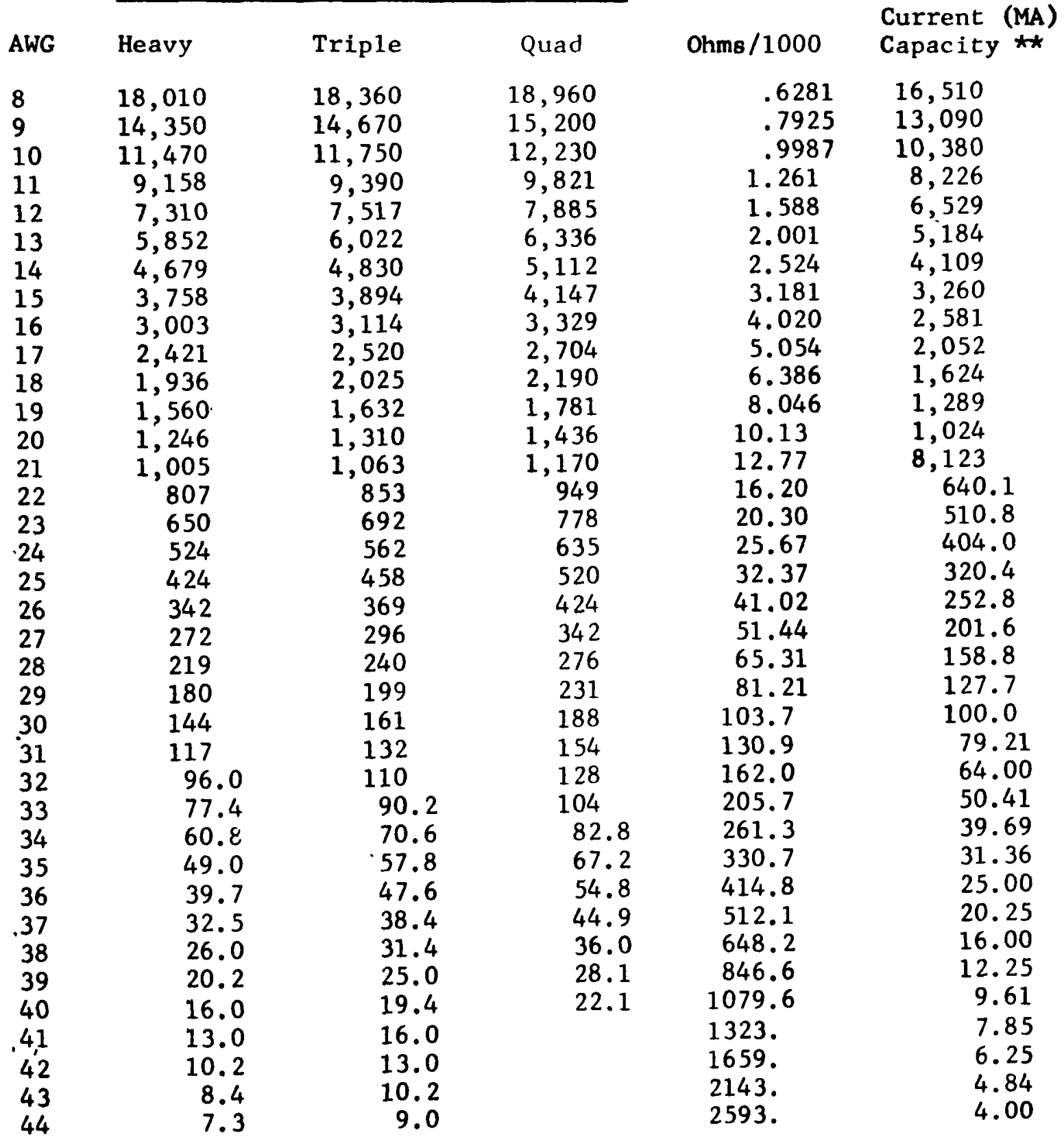

* Areas are for maximum wire area plus maximum insulation build up.

** Based on 1000 circular mils/amp current capacity will vary according to the geometry of the unit and may range from 750 . to 1200 sircular mils/amp. 